\title{
La escritura de Leopoldo María Panero
}

La literatura orgánica y el postestructuralismo

\section{Túa Blesa}

\section{(2) OpenEdition}

Journals

Edición electrónica

URL: http://journals.openedition.org/agedor/677

DOI: 10.4000 /agedor.677

ISSN: 2104-3353

Editor

Laboratoire LISAA

Referencia electrónica

Túa Blesa, «La escritura de Leopoldo María Panero », L'Âge d’or [En línea], 7 | 2014, Publicado el 01 marzo 2014, consultado el 01 mayo 2019. URL : http://journals.openedition.org/agedor/677 ; DOI : 10.4000/agedor.677 
Túa BLESA

Universidad de Zaragoza, Seminario de Investigaciones Culturales «Tropelías » (SIC) ${ }^{1}$

\title{
La escritura de Leopoldo María Panero: la literatura orgánica y el postestructuralismo
}

\begin{abstract}
Résumé : L'écriture de Leopoldo María Panero est une continuelle transgression des conventions établies, aussi bien en termes de contenus que de formes. Ce travail porte sur les conséquences qu'ont sur le sujet l'énonciation de ses livres dotée d'une double autorité, un je+je, sur l'usage de noms de formes littéraires tels que haikus, prose, etc., pour désigner des textes qui ne répondent pas aux règles attendues, mais aussi sur ses traductions singulières ainsi que les textes théoriques qui les accompagnent ; là, Panero propose en définitive ce que l'auteur de l'article nomme une « littérature organique », à savoir une proposition de littérature post-structuraliste: les exemples qui sont commentés ici en sont un témoignage.
\end{abstract}

Mots-clés : Leopoldo María Panero - Littérature organique - Post-structuralisme - Cadavres exquis - Formes littéraires - Traduction

Resumen: La escritura de Leopoldo María Panero es una continua transgresión de lo establecido, tanto en los contenidos como en lo formal. Este trabajo se centra en las consecuencias sobre el sujeto de la enunciación de sus libros de doble autoría, un yo+yo, en el uso de términos de formas literarias, haikú, prosa, etc., para designar textos que no cumplen las reglas de tales formas y también de sus singulares traducciones así como de los textos teóricos que las acompañan, donde Panero acaba proponiendo lo que el autor denomina "literatura orgánica", que no es sino una propuesta de literatura postestructuralista, de cuya práctica son testimonio los casos que aquí se comentan.

Palabras clave: Leopoldo María Panero - Literatura orgánica - Postestructuralismo - Cadáveres exquisitos - Formas literarias - Traducción

demás de su ya entonces no escasa obra poética, narrativa y ensayística, Leopoldo María Panero publicó en 1992 un libro de poemas escritos a dos manos, Cadáveres exquisitos y un poema de amor, en colaboración con José Luis Pasarín Aristi ${ }^{2}$, que inauguró lo que es hoy una nómina de hasta doce libros publicados con doble firma. El mencionado libro llevaba en el título la inequívoca expresión «cadáveres exquisitos», simple y bien reconocible traducción de la que los surrealistas habían utilizado, «cadavre exquis», para denominar unas prácticas de escritura que habrían comenzado en 1925 y a las que André Breton y Paul Éluard en el diccionario del surrealismo les dieron la siguiente definición:

\footnotetext{
${ }^{1}$ Este trabajo se inscribe en el marco del Grupo de investigación Seminario de Investigaciones Culturales «Tropelías » (SIC) del Gobierno de Aragón, cofinanciado con fondos FEDER.

2 PANERO, Leopoldo María, PASARÍN ARISTI, José Luis, Cadáveres exquisitos y un poema de amor, Madrid, Libertarias/Prodhufi, 1992.
} 
Jeu de papier plié qui consiste à faire composer une phrase ou un dessin par plusieurs personnes, sans qu'aucune d'elles puisse tenir compte de la collaboration ou des collaborations précédentes. L'exemple, devenu classique, qui a donné son nom au jeu, tient dans la première phrase obtenue de cette manière: Le cadavre - exquis - boira - le - vin nouveau. ${ }^{3}$

Jeu, juego, así lo definían quienes los llevaron a cabo, pero ese modo de escritura, ya esté doblado o no el papel ocultando lo ya inscrito cuando llega el turno del nuevo participante, este modo en el que el lugar del escritor es ocupado por los escritores podría parecer que sería puro entretenimiento, un quehacer intranscendente, cosas de niños, pero la cuasihomofonía jeu-je apunta a una cuestión central, a que se trata de un juego de toda seriedad. En efecto, la literatura como práctica, y la historia literaria y el pensamiento literario con ella, y aun la escritura en general se construye, salvo contadísimas excepciones, sobre la idea de yo, ego scriptor, y cuando se desconoce la identidad del individuo se acude al expediente de anónimo respondiendo así a la necesidad de un nombre al que atribuir la obra, un nombre aunque sea sin nombre propio, como bien observó Michel Foucault: «El anonimato literario no nos es soportable; sólo lo aceptamos en tanto que enigma» ${ }^{4}$. Pues bien, sobre esa construcción, un-texto-exige-un-autor, irrumpe el cadáver exquisito para ponerla en entredicho e incluso derrumbarla al quedar atribuido el texto a dos o más manos, a dos o más sujetos, a un múltiple, como mínimo doble, ego+ego scriptores, extraña figura para la enunciación.

Ahora bien, antes de continuar, convendrá dejar constancia de los títulos de la serie Panero-y-X y del nombre de $\mathrm{X}$ en cada uno de los casos: Cadáveres exquisitos, con el ya nombrado José Luis Pasarín Aristi, Tensó, escrito en colaboración con Claudio Rizzo ${ }^{5}, \mathrm{Me}$ amarás cuando esté muerto con José Águedo Olivares ${ }^{6}$ y con éste también ¿Quién soy yo? (apuntes para una poesía sin autor) ${ }^{7}$ —donde se incluye «Dormund», únicamente de Panero-, Presentación del Superhombre con Félix Caballero ${ }^{8}$ y con el mismo coautor Visión ${ }^{9}$, Apocalipsis de

\footnotetext{
${ }^{3}$ BRETON, André, ÉLUARD, Paul, Dictionnaire abrégé du surréalisme, París, José Corti 1991, s. v.

${ }^{4}$ FOUCAULT, Michel, «¿Qué es un autor?», Entre filosofía y literatura, intr. y trad. Miguel MOREY, Barcelona, Paidós, 1999, p. 329-360; la cita en p. 340.

5 PANERO, Leopoldo María, RIZZO, Claudio, Tensó, pról. LMP, epíl. Joaquín Marco, Madrid, Hiperión, 1997.

${ }^{6}$ PANERO, Leopoldo María, OLIVARES, José Águedo, Me amarás cuando esté muerto, Barcelona, Lumen, 2001.

7 PANERO, Leopoldo María, OLIVARES, José Águedo, ¿Quién soy yo? (apuntes para una poesía sin autor), pról. LMP y JAO, Valencia, Pre-textos, 2002.

8 PANERO, Leopoldo María, CABALLERO, Félix, Presentación del Superhombre, pról. LMP, Madrid, Valdemar, 2005.

${ }^{9}$ PANERO, Leopoldo María, CABALLERO, Félix, Visión, Madrid, Huerga y Fierro, 2006.
} 
los dos asesinos ${ }^{10}$, Jardin en vano ${ }^{11}$, Tango ${ }^{12}$, Voces en el desierto ${ }^{13}$, La tempesta di mare ${ }^{14}$ y La flor en llamas $^{15}$.

El abordar estos textos es complejo y el hecho es que en la bibliografía paneresca, adjetivo ahora poco adecuado, no hay trabajos que lo hagan. ¿Se trata de poemas verdaderamente escritos a dos manos? El lector no puede tener ninguna duda de la intervención de Panero en ellos: en general, el léxico es marcadamente paneresco, lo son también los asuntos y no menos las citas que se insertan, que repiten las que una y otra vez se leen en la, digamos, obra propia. Todo ello apunta a que la escritura de Panero está efectivamente en este conjunto de escritura plural.

Varios de estos libros contienen prólogos y en algunos de ellos se dicen cosas de interés sobre la cuestión de la autoría. Así, en el que abre Tensó, Leopoldo María Panero alude a la muerte del autor, menciona la práctica de la tensó provenzal, el cadáver exquisito, el renga japonés y la lien-tsu china, todos ellos muestras, cada una con sus peculiaridades, de la reunión de dos o más voces, y afirma que en los poemas del libro «se funden el trovar ric de Claudio Rizzo y el trovar clus de Leopoldo $\mathrm{M}^{\mathrm{a}}$ Panero, en un único texto en el que desaparecen los dos» y que «la tensó se ha convertido en una cosa o rizoma» ${ }^{16}$. Aunque obvias, haré dos anotaciones. La primera es que los adjetivos ric y clus designan en la poética provenzal un mismo estilo de escritura — frente al trobar len—, el difícil o hermético, con lo que las voces que aquí se fundirían entonan cantos de una única modalidad. En segundo lugar, la tensó ortodoxa, la practicada por los provenzales, es una sucesión de estrofas en las que alternan cada uno de los participantes, por lo que las dos voces quedan bien diferenciadas y además al principio de las dos primeras estrofas es usual que aparezca nombrado el oponente en el debate, aquel a quien se habla, lo que sirve en la lectura para la identificación de los poetas. Así, por ejemplo, en la tensó de Marcabrú y Hug Catola: «Amics Marchabrun» y «Ugo Catola» son los vocativos con que comienzan las dos primeras estrofas ${ }^{17}$.

10 PANERO, Leopoldo María, CABALLERO, Félix, Apocalipsis de los dos asesinos, Barcelona, La Garúa, 2006.

11 PANERO, Leopoldo María, CABALLERO, Félix, Jardín en vano, pról. LMP y FC, Madrid, Arena Libros, 2007.

12 PANERO, Leopoldo María, CABALLERO, Félix, Tango, pról. [s.a.], Las Palmas de Gran Canaria, el ángel caído, 2008.

13 PANERO, Leopoldo María, CABALLERO, Félix, Voces en el desierto, próls. LMP y FC, Valencia, azotes caligráficos, 2008.

14 PANERO, Leopoldo María, CABALlERO, Félix, La tempesta di mare, pról. FC, Barcelona, Huacanamo, 2009; la tercera sección, «Tragos», lleva la firma única de Panero, lo que excluye esos poemas de la serie de doble autoría.

15 PANERO, Leopoldo María, CABALLERO, Félix, La flor en llamas, Madrid, pról. LMP, Casus-Belli, 2011. Está además Locos de altar, Granada, Alea Blanca, que tiene como autores a Rubén Martín, Begoña Callejón y Leopoldo María Panero, pero a cada uno de ellos le corresponde una sección independiente.

16 PANERO, Leopoldo María, Tensó, op. cit., p. 9-10.

17 RIQUER, Martín de, Los trovadores. Historia literaria y textos, Barcelona, Planeta, 1975, 3 tomos, t. I, p. 192. En el citado prólogo escribe Panero que «es de todos conocida la tensó entre Raimbaut D’Aurenga y la Comtessa de Dia. En esta tensó se nos dice, en la parte proveniente de la Comtessa de Dia, que la poesía no sirve más que para ser comprendida, cal trovar non porta altre chaptal) (Tensó, op. cit., p. 9). Que la mujer que debate con d'Aurenga en la tensó a la que se refiere haya de identificarse con la Comtessa de Dia es asunto discutido y, por otra parte, sea ella o no la autora, la cita no pertenece a ese texto. Ni tampoco figura en los poemas de la Comtessa, sino que lo que Panero cita ha de ser «Que chans no port'altre chaptal», verso que se debe a Giraut de Bornelh en la tensó que mantuvo con Raimbaut d'Aurenga (véase RIQUER, Los trovadores, op. cit., t. I, p. 457). Es cita que LMP ha repetido en otros lugares, siempre con idéntica atribución. Cuando estaba preparando el primer volumen de su poesía completa, siendo que la frase en cuestión se lee en el prólogo de El último hombre (1983), le comenté al poeta que lo que él decía era erróneo y se podía y debía rectificar, pero no atendió a razones, ni siquiera a unas fotocopias que le envié al hospital de Las Palmas en 
Teniendo en cuenta lo anterior y que Tensó está compuesto de veinte poemas, ¿ha de entenderse que alterna la autoría de un poema a otro según el patrón Panero-Rizzo, o a la inversa, y el conjunto cumple la estructura de la tenso? Aunque, atendiendo a la afirmación de que se trata de «un único texto en el que desaparecen los dos» y la mención del rizoma, a lo que hay que añadir que más adelante se lee: «Esa poesía en común que hemos hecho imitando el cansancio de Deleuze sobre Guattari en un único rizoma» ${ }^{18}$, ¿ha de entenderse el conjunto de los veinte textos como escritura a dos manos? Eso parece. Apunta a esta atribución doble el que en el prólogo de otro de los libros de esta serie, Presentación del Superhombre, libro y prólogo que firman Panero y Félix Caballero, se dice: «Escribir a dúo, en contra de la poesía de auton» ${ }^{19}$ y que el título de otro de los prólogos también conjuntos, el de Jardín en vano, es «La escritura a dúo o acerca del misterio del águila bicéfala» ${ }^{20}$.

Como si respondiese al título de otro de los libros de esta serie, a ¿Quién soy yo?, el prefacio de Tango, sin firma y que, por tanto, habrá que atribuir a Panero y Caballero, se cierra con estas palabras: «No somos nadie, o somos ese nadie que corre más que yo, y he aquí que Tango anuncia el principio de una doble escritura, que no será una máscara del lenguaje» ${ }^{21}$, lo que viene a insistir en la doble autoría. Por su parte, en el siguiente de estos libros, Voces en el desierto, preceden a los poemas dos prólogos e importa atender a lo que se dice en el de Caballero:

Después de cinco años escribiendo con Leopoldo toda clase de obras: obras sólo suyas, en las que yo intervine sólo como amanuense; obras sólo mías, que él leyó y aprobó conmigo; y obras conjuntas, en las que yo escribía sobre lo que él había escrito un momento antes y viceversa. ${ }^{22}$

E importa, como he escrito, porque ahí se afirma sin ambages la doble autoría, la escritura de un autor que se superpone a la escritura de un segundo autor en una, al fin, escritura única, si bien doble. Así, por lo menos en lo que respecta a los poemas firmados por Panero y Caballero se cumple en ellos el ser, con expresión del prólogo a Tensó, rizoma, lo que, salvo informaciones que surgiesen y encaminasen a una solución distinta, habrá que extender a los poemas de toda la serie.

Rizoma, claro está, es término de Mille plateaux (1980) de Gilles Deleuze y Félix Guattari, uno de los libros decisivos del postestructuralismo, impugnación de la noción de sistema, de estructura, y que da título al prólogo, «Rhizome» — y de la importancia de tal prólogo habla el que se publicó previamente como texto independiente en 1976-. Mille plateaux sucedía a L'Anti-Oedipe (1972) y de hecho uno y otro no eran sino el primer y segundo tomo de Capitalisme et schizophrénie, título de la obra global. Pues bien, «Rhizome», Mille plateaux, comenzaba declarando que «El Anti-Edipo lo escribimos a dúo», como, por otra parte, se anunciaba en la doble firma. Así, lo que el surrealismo había iniciado, bien

donde residía. Siendo, pues, su voluntad mantener el error, así se editó, «cal trovar non porta altre chaptal (porque cantar no recibe otro capital) como afirmara la Comtessa de Dia», PANERO, Leopoldo María, Poesía completa 1970- 2000, ed. Túa Blesa, Madrid, Visor, p. 288, y, no siendo una edición anotada, quedó sin advertencia ninguna. No es el único caso de errores mantenidos en los dos volúmenes de Poesía completa, sino que, no pudiendo convencer al poeta, son otros más los que quedaron sin enmienda. Añadiré que durante la preparación de uno y otro libro, le hice una serie de consultas y sugerencias y, así como en algunos casos fue razonable, en otras, como la que ha promovido esta nota, fue tajante.

18 PANERO, Leopoldo María, Tensó, op. cit., p. 14.

${ }^{19}$ PANERO, Leopoldo María, CABALLERO, Félix, Presentación del Superbombre, op. cit., p. 11.

20 PANERO Leopoldo María, CABALLERO, Félix, Jardín en vano, op. cit., p. 7.

${ }^{21}$ PANERO Leopoldo María, CABALLERO, Félix, Tango, op. cit., p. 6.

22 PANERO Leopoldo María, CABALLERO, Félix, Voces en el desierto, op. cit., p. 9. 
que con otras manifestaciones anteriores más o menos asimilables, el trasladar del yo al yo+yo la responsabilidad autorial, lo hacía suyo ahora el discurso filosófico. Así, estos dos libros han de figurar junto a los de Leopoldo María Panero-y-X en la serie de, digamos, cadáveres exquisitos, ya no de la literatura, sino de un campo mucho más amplio de la cultura. Allí mismo Deleuze y Guattari se preguntan «¿Por qué hemos conservado nuestros nombres?» para responder a continuación: «Por rutina, únicamente por rutina. Para hacernos nosotros también irreconocibles [...]. No llegar al punto de ya no decir yo, sino a ese punto en el que ya no tiene ninguna importancia decirlo o no decirlo. Ya no somos nosotros mismos» ${ }^{23}$, lo que encuentra su correspondencia en la afirmación «ya no se sabe quién escribe» del prólogo de Tensó. Y la respuesta parece venir dada en Mil mesetas:

Un libro no tiene objeto ni sujeto, está hecho de materias diversamente formadas, de fechas y velocidades muy diferentes. Cuando se atribuye el libro a un sujeto, se está descuidando ese trabajo de las materias, y la exterioridad de sus relaciones. Se está fabricando un buen Dios para movimientos geológicos. ${ }^{24}$

Así, habrá que entender que los poemas de Cadáveres exquisitos, de Tensó y los que le suceden en la serie firmada por Leopoldo María Panero-y-X son ejemplares de ese libro rizomático, sin objeto ni sujeto, de esa escritura que rehúye a un buen Dios y se presenta como fluido por donde discurren flujos. Flujos de escritura, de escrituras, de pensamiento, de pensamientos, flujos de yoes.

El caso es que Panero, al elaborar libros de poesía con X, no era desconocedor ni de los cadáveres exquisitos surrealistas ni de la problematización del yo de la enunciación, por no decir del borrado o del emborronado al menos, que habían dejado Deleuze-Guattari en los mencionados libros y ello sitúa ya su escritura en la salida del estructuralismo que tiene por nombre postestructuralismo.

Este poner en jaque al yo por parte de Panero no quedaba inaugurado con Cadáveres exquisitos, sino que la operación estaba ya presente en textos anteriores. Al respecto es decisivo lo que se lee en la contraportada del segundo de sus libros de poesía, Teoría. Allí, tras aludir a lo que era ya su personaje literario, su personalidad en la institución literaria, al que se refería como «esa ficción», escribió:

ese golem [que] nació hace unos años, con motivo de una ficción más amplia aún y más burda, que llamóse «generación», ficción esta última a la que dio pie José María Castellet con su antología de presuntos infames, llamada novísimos [...] y al fin murió, dejando sólo ese on tis que es el que escribe,

para concluir refiriéndose a «esa persona que de sí misma reniega» 25 . La firma de ese libro, pues, era de la ou tis, un nadie que había renacido sobre la muerte de Leopoldo María Panero, un ou tis, otro que se nombra como nadie y que ha de leerse como variante del «ya no somos nosotros mismos» de Deleuze y Guattari o a la inversa.

\footnotetext{
23 DELEUZE, Gilles, GUATTARI, Félix, Mil mesetas. Capitalismo y esquizofrenia, trad. José Vázquez Pérez, Valencia, Pre-textos, 1988, p. 9.

${ }^{24}$ Ibid.

25 PANERO, Leopoldo María, [contraportada], Teoría, Barcelona, Lumen, 1973, en Poesía completa 1970- 2000, op. cit., p. $77-78$.
} 
En «Prescripciones» ${ }^{26}$ señalé cómo una de las manifestaciones del postestructuralismo en literatura es el uso de los términos que designan a las formas textuales en un sentido diríase que figurado. Es decir, nombrar como «soneto», por ejemplo, a un texto que no se ajusta a las normas que la tradición ha venido respetando, tal como sucede cuando Arthur Rimbaud titula «Sonnet» la segunda parte de su «Jeunesse»en Illuminations y que resulta ser un poema en prosa. Mencionar este antecedente deja claro que las prácticas postestructuralistas no son exclusivas de nuestro tiempo, como tampoco el pensamiento estructuralista se corresponde con lo que se suele señalar como período estructuralista, como con tanto acierto advirtió en diversas ocasiones Jacques Derrida. Lo que «Sonnet» como título de un texto que dista tanto de estar organizado como soneto cuanto que está en prosa supone es que las reglas compositivas que los términos literarios prescriben - es decir, dictan, imponen - y prescriben — es decir, cesan, caducan- y los dos modos de prescripción se dan a un tiempo, en un mismo texto, de ahí el plural prescripciones. $\mathrm{Y}$ el resultado es que el término en cuestión, «soneto» en este caso, y el texto al que da nombre, que incumple las reglas del soneto, establecen un conflicto irresoluble: se nombra soneto lo que no lo es y ninguna de esas dos realidades puede llegar a ser anulada por la otra, quedando como verdad tanto la una como la otra en una dialéctica cuya síntesis se difiere indefinidamente. A esta propiedad de los términos literarios para nombrar, en lo que es un uso figurado al tiempo que designación directa, textos, la he denominado interminabilidad, una interminabilidad que es, como queda dicho, propia de los términos ${ }^{27}$.

Siendo que las formas literarias conforman un sistema, un sistema que es un entramado de estructuras, el uso figurado de los términos que dan nombre a esas formas en virtud de la interminabilidad de los términos, su función como prescripciones, produce la desestructuración del sistema, hace surgir la desestabilización sobre la que, sin atender a ella, resultó establecido el sistema.

La obra de Panero ofrece casos semejantes al ejemplo rimbaldiano. Algunos de ellos pertenecen a la serie de haikus que se reparten por varios de sus libros. Así, en Teoría, "Quemar a Kafka»», cuyo subtítulo indica la adscripción genérica, «haikú», consta de tan sólo dos versos (aunque entre las dos líneas hay otra más que acoge un punto), de manera que no cumple ni siquiera la prescripción de los tres versos canónicos, prescripción que, por tanto, prescribe. Mayor alteración se da en este otro texto:

Le bon Pasteur (Haikú)

Es duro el trabajo de la pesadilla,

es duro

arrastrar de día el carro de las marionetas,

de noche; y ser una de ellas

mañana, cuando abran los ojos

para no ver

que la bailarina de cuerda danzando entre ellas

mueve ella misma el resorte. ${ }^{29}$

${ }^{26}$ BLESA, Túa, «Prescripciones», Signa. Revista de la Asociación Española de Semiótica, 10, 2001, p. 219-232.

27 BLESA, Túa, «Barthes, Derrida, etc. y la interminabilidad», Conjunciones. Jacques Derrida y compañia, eds. Cristina de Peretti y Emilio Velasco, Madrid, Dykinson, 2007, p. 218-231.

${ }^{28}$ PANERO, Leopoldo María, Teoría, op. cit., p. 123.

${ }^{29}$ PANERO, Leopoldo María, Narciso en el acorde último de las flautas, Poesía completa 1970-2000, op. cit., p. 188. 
Como es evidente - de no ser porque así se indica- ni por el número de versos, ni por la no presencia de la palabra de estación, ni por lo que en éstos se dice, el lector podría pensar que está ante un haiku.

Otra muestra de prescripciones se lee en los dos poemas que llevan la indicación de estar adscritos a la forma limerick, el que va encabezado por la leyenda «LSD Limerick» y «Prosiguiendo (persiguiendo) a Lear» ${ }^{30}$, donde también se lee en el encabezamiento «Limerick». Copio el primero de ellos:

\section{LSD limerick.}

Alicia en el llano sonaba

con rojo teji.ó su baba

un viejo en la cruz ágata

en lámpara viejo oro y cruz

esquizofrénico niño mas

un viejo que en el yano hablaba.

Si se exceptúa la mención de «un viejo», tan repetida en los limericks de Lear, que están entre las lecturas de Panero, no hay nada ni en la forma ni en lo que el texto dice que recuerde el tipo de estrofa que el epígrafe invoca.

Una nueva doble prescripción la ofrece el poema «Necrofilia (prosa)», que, pese a tal indicación, es un poema en verso:

El acto del amor es lo más parecido

a un asesinato.

En la cama, en su terror gozoso, se trata de borrar

el alma del que está,

hombre o mujer,

debajo.

Por eso no miramos.

Eyacular es ensuciar el cuerpo

y penetrar es humillar con la

verga la

erección de otro yo.

Borrar o ser borrados, tanto da, pero

en un instante, irse

${ }^{30}$ PANERO, Leopoldo María, Teoría, op. cit., p. 128; se da ahí la doble prescripción, aunque ha de anotarse, al menos, que la mención de «un viejo» acerca el poema a no pocos de los de Edward Lear que Panero conocía bien, pues había publicado el año anterior a Teoría, en 1972, una selección de limericks de Lear traducidos, El ómnibus, sin sentido, Madrid, Visor. El segundo de los textos mencionados, Narciso en el acorde último de las flautas, op. cit., p. 148, tiene un primer verso, «Érase una vez la niña en Praga», en el que se cumple el código. De hecho, quizá sea traducción, bajo los singulares criterios panerescos, de «There was an Old Lady of Prague», inicio de uno de los textos del autor inglés que Panero tradujo con el siguiente resultado: «Había una vez una niña en Praga», véase El ómnibus, sin sentido en PANERO, Leopoldo María, Traducciones/Perversiones, ed. Túa BLESA, Madrid, Visor, 2011, p. 73; el resto del limerick ya no guarda relación con el traducido. 
dejarlo

una vez más

entre tus labios. ${ }^{31}$

¿Prosa, según advertía el epígrafe? No, versos. Como queda a la vista, hay páginas en la escritura de Leopoldo María Panero que ponen en crisis alguna de las estructuras del sistema literario y, por tanto, al sistema en su conjunto, pues la práctica de las prescripciones no afecta a esta o aquella forma literaria, sino que, por cuanto una alteración en uno de los elementos del sistema lo desestabiliza por completo, denominar haiku o limerick a textos que no se ajustan a las reglas compositivas que se resumen en tales términos, o adjudicar a unos versos la etiqueta de prosa, desestructura a todo el conjunto.

Aunque la obra poética de Panero casi ha eclipsado sus textos narrativos, lo cierto es que éstos son de todo interés y no faltan en ellos algunos casos en los que se pone también de manifiesto un quehacer postestructuralista. En 1976 se publicó En lugar del bijo, un conjunto de relatos, el primero de los cuales, «Acéfalo» ha de traerse a estas páginas ${ }^{32}$. El punto de partida es la historia que recogió Dante en el canto XXXIII del «Inferno» en su Commedia, en la que el conde Ugolino della Gherardesca cuenta al caminante cómo, encerrado en una torre junto a sus hijos, hubo de pasar por el trance de verlos morir de inanición y, urgido él mismo por el hambre, acabó devorando los cadáveres. Si la Commedia es uno de los textos que una y otra vez reaparecen por sus escritos, está claro que la historia de Ugolino había de atraer la atención de Panero, pero lo que importa aquí es que el relato en cuestión tiene como subtítulo «Proyecto de un cuento» y no es una expresión en vano, sino que el tal cuento se ofrece a la lectura en forma de proyecto, no, pues, de cuento acabado, aún no texto definitivo. En efecto, desde la primera línea el texto consiste en las indicaciones con las cuales se podría, o debería, escribir el cuento, cuento que está, pues, por escribir. «Descripción de la Torre de Gualandi» son las palabras iniciales, torre que, como consecuencia de ser un proyecto, no se describe, si bien se dan las pautas para realizarla: «descripción que ha de ser fría, objetiva, geométrica, en modo alguno poética: como, si quien mirara, no fuera el autor, ni ningún otro hombre, sino el objetivo insensible de una cámara cinematográfica» ${ }^{33}$. De este mismo modo, distanciado de los hechos narrados, continúa el relato, véase, por ejemplo, el pasaje en que el padre se come al menor de sus hijos:

\footnotetext{
31 PANERO, Leopoldo María, El que no ve, Madrid, La banda de Moebius, 1980, Poesía completa 1970-2000, op. cit., p. 244.

32 PANERO, Leopoldo María, En lugar del bijo, Barcelona, Tusquets, 1976. Durante la preparación de la edición de Cuentos completos, Madrid, Páginas de espuma, 2007, hice varias consultas al escritor sobre algunas de las correcciones que creía yo debía introducir. En una de aquellas conversaciones, me insistió en que el título correcto del mencionado libro era El lugar del hijo, por lo que apareció así en la recopilación.

33 PANERO, Leopoldo María, Cuentos completos, op. cit., p. 37. La mención de la "cámara cinematográfica» invita a recordar que otro de los relatos de El lugar del hijo, el titulado «Hortus conclusus», es un guion cinematográfico y así se presenta: «Guión cinematográfico basado en Peter Pan de James Mathew Barrie y en The wicked voice de Vernon Lee, con destino a un cortometraje en blanco y negro y de una duración aproximada de 15 minutos», ibid., p. 157. J. Benito Fernández afirma que tal guion sí iba a ser efectivamente rodado (El contorno del abismo. Vida y leyenda de Leopoldo María Panero, pról. Antonio Martínez Sarrión, Barcelona, Tusquets, 1999, p. 145), en cualquier caso la disposición del texto es la de un guion con sus indicaciones de plano, cámara, etc., características. Por otro lado, «The wicked voice» de Lee fue traducido por Panero con el título «La voz maldita» en Visión de la literatura de terror anglo-americana, Madrid, Felmar, 1977, p. 35-70, traducción a la que me referiré más adelante.
} 
Sin la concesión a la humanidad que supondría explicar el proceso psicológico que lleva a il conte a devorar a su hijo muerto, explicación que sería inútil, a más de falsa, dado que la decisión de hacerlo ha de cortar inevitablemente toda continuidad psicológica, vemos a Ugolino en el acto de hacerlo, devorando a Gaddo desde la óptica de una voluntad cualquiera. ${ }^{34}$

En actitud que compartía con otros escritores de la época, Panero al igual que en sus poemas resultaba ser un renovador en toda su escritura y es a ese impulso emergente entonces en la literatura española al que responde el modo en que se narra la terrible historia dantesca, pero lo relevante para estas páginas es que el relato se presenta, y se redacta, como el proyecto del relato, un proyecto, diríase que un borrador, un guion sobre el que trabajar posteriormente, un proyecto que, sin dejar de serlo, es ya el relato proyectado, de manera que la estructura proyecto-de-texto/texto, borrador/texto-definitivo, o como se prefiera enunciarla, resulta alterada, toda vez que los dos miembros de la oposición, que en principio no pueden confundirse e incluso guardan entre ellos un orden temporal, lapso que ahora se reduce a nada, lo que los instituye como co-presentes y están actualizados en un escrito único que participa de los dos valores confrontados. Ello supone de nuevo, como es notorio, un fenómeno de prescripciones: el borrador, el proyecto, es ya el texto.

Los géneros memorialísticos implican la verdad de lo relatado, el ajustarse a la historia, bien que, es bien sabido, en ocasiones el autor caiga en olvidos o magnifique algunos de los acontecimientos de su vida. Panero, cuya obra está hecha en gran parte de transgresiones de todo tipo, no es ajeno a las violaciones de la verdad en sus páginas autobiográficas. Dejando aparte ahora el que no faltan en sus poemas elementos traídos de la memoria, haré referencia a algunos pasajes de sus narraciones. En ellas, en ocasiones, la anécdota es introducida por expresiones que informan al lector de la veracidad de lo que se cuenta. Así, por ejemplo, se lee en «Páginas de un asesino (novela inacabada)» de Palabras de un asesino: «Todavía me acuerdo, las calles de Tánger, sin un dirbam en el bolsillo» ${ }^{35}$, y J. Benito Fernández en su siempre bien informada biografía de Panero, El contorno del abismo, da noticia de hasta seis viajes del poeta a dicha ciudad marroquí —en 1969, 1970, 1971, 1972, 1976 y 1986 - de las que las cinco primeras son anteriores a la publicación del texto citado -1984-, por lo que ese recuerdo puede remitir a cualquiera de ellas, no siendo las estrecheces económicas un dato que suministre alguna pista sobre cuál pudiera $\operatorname{ser}^{36}$.

Pues bien, en Prueba de vida. Autobiografía de la muerte, además de que convendrá no pasar por alto lo que el subtítulo dice, antobiografía, se lee que se trata de un «relato de la verdad ${ }^{37}$. Y, teniendo en cuenta todo esto, el lector llega al siguiente pasaje:

vi que era una esperanza el delito y el crimen, y la ofensa a los dioses; y así empuño una espada contra el hombre, lo que me lleva a escribir, sobre este papel húmedo e idiota, mi lista de crímenes: yo he matado a mi madre, soy el Anticristo y el asesino de su madre, j'ai tué l'esprit. Yo he matado a Jean-Paul Sartre, poseyéndolo como a una muñeca hinchable, como

\footnotetext{
${ }^{34}$ Ibid., p. 41.

35 PANERO, Leopoldo María, Cuentos completos, op. cit., p. 235; la cursiva es mía. Palabras de un asesino (1992) se publicó primero, en 1984, con el título Dos relatos y una perversión.

${ }^{36}$ FERNÁNDEZ, J. Benito, El contorno del abismo. Vida y leyenda de Leopoldo María Panero, op. cit., pp. 142, 148, 156, 164, 208 y 287. En cuanto a las estrecheces económicas no estará de más anotar que al relatar el viaje a Tánger de 1970, Fernández escribe que Panero y Jesús Sainz tuvieron que abandonar a mitad del viaje un ómnibus que les conducía a Essaouira «Sin un dirham en los bolsillos», p. 148.

${ }^{37}$ PANERO, Leopoldo María, Prueba de vida. Autobiografía de la muerte, Madrid, Huerga y Fierro, 2002, p. 45.
} 
un escarabajo, que eso es lo que era; yo he matado a Dámaso Alonso; yo he matado a Luis Rosales como dice estúpidamente la televisión; yo he matado a Jacques Lacan, y me gusta leerlo, encendiendo porros usando como filtro un trozo de cartón de la portada de sus écrits; yo he matado a Roland Barthes [...]. Yo he matado a Herbert Marcuse porque amenazaba con venir a España, yo he matado también a Ronald D. Laing, el antipsiquiatra ${ }^{38}$,

lista de crímenes que se continúa en Papá, dame la mano que tengo miedo. Allí, a pesar de la declaración «No soy un asesino, aunque a veces juegue a serlo» ${ }^{39}$, y la matización sobre uno de los asesinatos declarados en la cita anterior, «Luis Rosales, un poeta cuya muerte me atribuí»", se añade una nueva víctima a la serie de asesinatos, o asesinatos en serie, "Gastón Baquero, un poeta al que asesiné», lo que se reitera enseguida en el texto: «Yo maté a Gastón, mi querido Gastón» ${ }^{41}$.

Todo ello informa de una nada desdeñable cadena de confesiones de asesinatos que deberían ser merecedores de una dura condena. De ser cierto lo que se dice, claro, como claro es para cualquier lector que en ese pasaje la referencialidad exigida a la escritura autobiográfica se ha desvanecido y lo que esas frases afirman habrá que adscribirlo a lo fantástico. Y no faltan, por otra parte, las noticias que se ajustan a la historia, como los internamientos en establecimientos psiquiátricos, el traslado de Mondragón a Las Palmas de mano de Claudio Rizzo y varios otros asuntos más, que tienen su verdad bien documentada. Pero claro es también que lo autobiográfico y lo fantástico ocupan lugares diferenciados, opuestos, en el sistema literario, de manera que confesiones, por continuar llamándolas así, como «Yo he matado a Jean-Paul Sartre», etc., u otras declaraciones como «si Jesucristo resucitó una vez, yo he resucitado cuarenta» ${ }^{42}$ producen en el sistema alteraciones que desmontan algunos de sus componentes, de sus estructuras y, en consecuencia, el sistema mismo, incapaz ya de dar cuenta de textos de lo que habrá de calificarse de autobiografía fantástica. Y hay que agregar a todo esto que en «Palabras de un asesino», texto que el autor califica de autobiográfico, «una autobiografía novelada mía que se llama Palabras de un asesino» ${ }^{43}$, Panero reitera, entre recuerdos de su pasado, sueños y otros materiales, ser un asesino: «Mais oui, certainement j'ai tué. Et peut-être je tuerai encore. Seulement qu'on peut pas le démontrer» ${ }^{44}$.

\footnotetext{
38 Ibid., p. 84. Como es evidente, donde dice «écrits» debe leerse «Écrits», el conocido libro de Lacan. Valga esta nota para dejar constancia de los poco limpios originales de Panero (véase, por ejemplo, Conjuros contra la vida, facsímiles de textos mecanografiados incluidos en Federico UTRERA, Después de tantos desencantos. Vida y obra poéticas de los Panero, Las Palmas de Gran Canaria, Festival Internacional de cine, 2008, p. 263-331) y del descuido, muy generalizado, de los editores de los libros de Panero, que han dado a la estampa los originales con sus errores y aun los más evidentes. Recordé en otra ocasión, en la nota «Esta edición» en PANERO, Leopoldo María, Cuentos completos, op. cit., p. 27, que Jenaro Talens, al comentar cómo la obra de Panero es ajena a la artisticidad, y es un juicio irrebatible, señaló el descuido de sus textos como índice claro de ello (TALENS, Jenaro, «De poesía y su(b)versión (Reflexiones desde la escritura denotada "Leopoldo María Panero”)», PANERO, Leopoldo María, Agujero llamado Nevermore, Madrid, Cátedra, 1992, p. 9-62). Ello no empece para que a la hora de editar textos, jaun los de Panero!, se deba intentar limpiar los errores, lo que en este caso es casi labor inagotable.

39 PANERO, Leopoldo María, Papá, dame la mano que tengo miedo, pról. Ana María MOIX, Barcelona, Cahoba, 2007 , p. 85.

40 Ibid., p. 37.

${ }^{41}$ Ibid., p. 117 y 119. En la primera de las citas he corregido «Baquet» por «Baquero». Ha de referirse al poeta Gastón Baquero (Banes, Cuba, 1914-Madrid, 1997), quien, exiliado tras la revolución castrista, se instaló en Madrid, donde entre otras ocupaciones trabajó en el Instituto de Cultura Hispánica, en el que también trabajó Leopoldo Panero, con quien tuvo amistad.

42 PANERO, Leopoldo María, Prueba de vida. Autobiografía de la muerte, op. cit., p. 33.

43 Ibid., p. 79.

${ }^{44}$ PANERO, Leopoldo María, Palabras de un asesino, Cuentos completos, op. cit., p 252.
} 
Por supuesto que siempre se podría recurrir al expediente de «escritura de la locura», aunque no se sabe bien qué funcionalidad pudiera tener si de lo que se habla es de literatura, de textos, eso sí, sería semejante a hablar de «pintura de la locura» para juzgar los cuadros de Van Gogh. Ejemplos de prejuicio y, como crítica, de una crítica de la indigencia.

Por otra parte, entre las formas textuales pendientes de la memoria, es, si no regla, si muy general la ordenación de los materiales según el orden cronológico. Claro que éste puede sufrir alteraciones, como acontecimientos que se anticipan, saltos a momentos ya pasados. Ahora bien, dentro de estas formas, el diario está más sometido a la ordenación temporal e incluso ésta viene marcada corrientemente por un incipit con la fecha. Pues bien, Panero va a introducir un curioso desorden, uno más, en las fechas de las anotaciones en su «Diario del manicomio de Mondragón. Relación de un asesinato», del que copio sus encabezamientos: «6 de enero», «5 de enero», «4 de enero», «3 de enero», «6 de enero», «4 de enero», «3 de enero», «4 de enero», «6 de abril», «7 de abril»», «20 de abrill» ${ }^{45}$, donde como se ve, las anotaciones vuelven atrás o avanzan en una cronología de lo más particular, consignan un tiempo dislocado, lo que es un nuevo ejemplo de las transformaciones de las formas literarias que se dan cita en las obras de Panero.

Además de su obra propia, en el sentido usual de tal adjetivo, está la obra apropiada, las traducciones, las singularísimas traducciones, tan singulares que acaban exigiendo para sí el ser calificadas como textos apropiados, hechos propios. Unas traducciones, por otra parte, que incluyen textos poéticos y también narrativos ${ }^{46}$. Tanto en unos como en otros Panero no cumple la función clásica del traductor, la que tiene como objetivo, aunque sea pura imposibilidad, el reproducir en otra lengua el original, el contenido del original, sino que su tarea de traductor va a ser la de intervenir en el texto con modificaciones y, sobre todo, con añadidos, interpolaciones que hablan más de un autor que de un traductor. Veamos alguno de los casos. El relato «La visión» de El lugar del hijo se presenta con la advertencia de ser "Adaptación de "La lente de diamante" de Fitz-James O’Brien» y, en efecto, el término «adaptación» no es en vano. En el momento en que el narrador da noticia del extraordinario poder del microscopio que posee, se lee:

No hablaba a nadie de mis placeres solitarios, como si se bubiera tratado de ese «pecado solitario» que es la metáfora de toda práctica absoluta y en el que el semen acoge la soledad con júbilo, ya que se sabe la sustancia de Dios y lo absoluto está solo y es también lo — que el hombre al menos considera- más inmundo. Como quien se masturba, también tenía toda una imaginería en secreto. $Y$ con mi microscopio, semejando a un falo erigido frente a un abismo que es atracción y amenaza (el mundo del cristal de prueba), me encerraba en mi habitación y me estropeaba los ojos ${ }^{47}$,

donde todo lo marcado en cursiva ha sido leído en un original fantasmal, es decir, añadido por el «traductor» en lo que es un ejercicio de escritura sin más o, si se prefiere, de escritura primera y no segunda que es como se suele considerar la traducción. Y, como he advertido, no es un caso extraordinario en la obra traducida, y apropiada, de Panero, véanse, por ejemplo, el párrafo final de «A wicked voice» de Vernon Lee y el de su versión en Visión de la literatura de terror anglo-americana, donde de nuevo he señalado en cursiva lo interpolado:

\footnotetext{
45 PANERO, Leopoldo María, «Diario del manicomio de Mondragón. Relación de un asesinato», Globo rojo. Antología de la locura. Recopilación de textos enfermos mentales del Sanatorio de Mondragón, al cuidado de Leopoldo María PANERO, Madrid, Hiperión, 1989, en Poesía completa 1970-2000, op. cit., p. 373-375.

46 Para los detalles remito a mi «Teoría (y práctica) de la traducción como perversión», PANERO, Leopoldo María, Traducciones/Perversiones, ed. Túa BLESA, Madrid, Visor, 2011, p. 7-39.

${ }^{47}$ PANERO, Leopoldo María, «La visión», Cuentos completos, op. cit., p. 125.
} 
O wicked, wicked voice, violin of flesh and blood made by the Evil One's hand, may I not even execrate thee in peace; but is it necessary that, at the moment when I curse, the longing to hear thee again should parch my soul like hell-thirst? And since I have satiated thy lust for revenge, since thou hast withered my life and withered my genius, is it not time for pity? May $\mathrm{I}$ not hear one note, only one note of thine, $\mathrm{O}$ singer, $\mathrm{O}$ wicked and contemptible wretch?

¡Oh, voz, voz maldita, violín de carne y sangre construido por la mano enferma del Maligno, por el poder negador del dios loco! ¿Ni siquiera, oh, voz, puedo execrarte en paz? ¿Es preciso que en el momento en que te maldigo el deseo de oírte una vez más tenga que incendiar mi alma como una sed del Infierno? Y ahora que ya has saciado tu sed de venganza, ahora que puedes celebrarla pastando entre las ruinas de mi alma el musgo que únicamente crece en ellas, puesto que has aniquilado mi vida y lo que en ella tapaba su ridículo, mi genio, ¿no es tiempo para la piedad? ¿Podré dejar de oír una nota, sólo una nota, estructurada por tu voz con carne y sangre, con la incurable pobreza de la materia, me concederás al menos una pausa, un intervalo de silencio en que pueda dejar de oirte, de oírte decir "siempre", joh!, cantante, joh!, ser abyecto y despreciable? ¿Es que acaso no sabes otra palabra, otra razón que la que dice "para siempre"?48

Otro de los que merecen ser señalados es el comienzo de The hunting of the Snark de Lewis Carroll, donde los ocho versos del original producen en el nuevo texto nada menos que veinte, o los versos de la estrofa XI de Childe Roland to the dark tower came de Robert Browning que se expanden notablemente y son varios otros más los que se podrían y deberían citar aquí, lo que me llevó a proponer que el trabajo de traductor de Panero responde a la operación retórica de la amplificatio ${ }^{49}$. Y, si acudimos a los limericks de Edward Lear, las transformaciones son sorprendentes: «an Old Lady» pasa a ser «una niña» ${ }^{50} \mathrm{y}$ 《an Old Man» pasa a ser «un joven» ${ }^{51} \mathrm{y}$ el lector interesado encontrará muchos otros pasajes en estas originales traducciones.

Esta faceta de Panero como traductor es en sí misma de todo interés, pero lo es mucho más porque su práctica ha ido acompañada de textos teóricos que, si bien tratan de explicar los peculiares resultados de su tarea, o justificar — «para justificarme» escribe tras exponer algunos de sus principios en el prólogo a El ómnibus, sin sentido ${ }^{52}$ - su originalidad, y el caso es que el alcance de sus exposiciones excede esa cuestión y llega a plantear cuestiones centrales del pensamiento literario con propuestas que sobrepasan de nuevo el estructuralismo.

Es decisiva en la tarea del traductor llamado Leopoldo María Panero su convicción de que el traductor no es un escritor de segundo orden, sino de orden tan primero como el denominado autor pueda serlo y es eso lo que explica, o justifica para decirlo con expresión suya, sus intromisiones en el texto, ya desarrollando el original, ya inscribiendo términos en lugar de otros que un diccionario no ofrecería, como cuando traduciendo un soneto de Georges Bataille «les chemins égarés de ta bouche profonde» se convierte en «el camino perdido de tu ano profundo ${ }^{53}$, si bien el lector de Bataille, por ejemplo el de Histoire de l'oeil, entenderá bien la mutación anatómica y, ¿por qué no decirlo?, el acierto en la traducción.

Dado que el traductor escribe, Panero utiliza diversas denominaciones distintas de la usual para sus trabajos. Así, «La visión»es, según ya ha quedado señalado «adaptación», expresión que se repite en el encabezamiento de «Medea», "Adaptación del relato del

\footnotetext{
48 PANERO, Leopoldo María, Visión de la literatura de terror angloamericana, op. cit., p. 70.

49 BLESA, Túa, Leopoldo María Panero, el último poeta, Madrid, Valdemar, 1995, p. 88.

${ }^{50}$ PANERO, Leopoldo María, Traducciones/Perversiones, op., cit., p. 73.

${ }^{51}$ Ibid., p. 82.

52 PANERO, Leopoldo María, «Lo que por fin dijo Benjamin», El ómnibus, sin sentido, Madrid, Visor, 1972, p.

7-8; la cita en p. 7.

53 PANERO, Leopoldo María, Traducciones/Perversiones sop., cit., p. 214.
} 
mismo nombre de Fitz-James O'Brien ${ }^{54}$ —aunque hay que anotar que el título del original no es idéntico, sino «The mother of pearl»—; por su parte, la traducción de «The inmost light» de Arthur Machen lleva la advertencia de Panero en «Dos prefacios para un título», con la noticia de la fuente, de que

sólo parcialmente me pertenece [...] aun siendo de Machen, también en cierta forma me pertenece no sólo por la traducción, sino porque creo que de todos son conocidas mis liberalidades - yo diría mejor, libertades - que me tomo al traducir: corrijo más que traduzco 55

Traducir, pues, será en este corpus un ejercicio de escritura, de corrección, tal como se deja dicho en la introducción a $V$ isión de la literatura de terror anglo-americana:

En lo que concierne a la traducción, he corregido y tratado de perfeccionar en ella, como suelo hacer, y sin el menor respeto por la cultura, la textura de los cuentos, y sobre todo sus finales, que son el momento siempre clave en el cuento, como Poe intuyó, pero sobre todo en el relato terrorífico. Que me perdonen quienes custodian el discurso por lo que aquí he dejado salir. ${ }^{56}$

Cuando traduce el soneto de Bataille antes aludido, no teniendo título, Panero le adjudica el de «Mutación de Bataille», con palabra bien expresiva de la operación que se ha llevado a cabo y además se recoge, junto a otras traducciones, en la sección de Narciso en el acorde último de las flautas (1979) que tiene como epígrafe «Palimpsestos» ${ }^{57}$, expresión no menos significativa; antes, en la sección «Sobre la traducción» del prólogo a Matemática demente (1975), se refería a sus traducciones como «deliberadamente pervertidoras» ${ }^{58}$. Así, para referirse a sus traducciones Panero prefiere, en lugar de traducción, otros términos: adaptación, corrección, mutación, palimpsesto y perversión.

Es el mencionado «Sobre la traducción» un texto importante para lo que es el pensamiento de Panero sobre la traducción, pues no sólo aparece en él el término per-versión — se refiere a su traducción de los limericks de Lear como «versión, o perversión» ${ }^{59}$ —, un término con el que se trataría de superar los modos de traducción clásicos, canónicos, que serían prácticas de una escritura subalterna sometida a la hegemonía del original, para decirlo con palabras de Antonio Gramsci. La perversión, al trasladar textos sin poner límites a las liberalidades o libertades, sacaría a esa forma de escritura de esa situación de subalternidad, la liberaría.

En el mencionado prólogo, escribe Panero que «toda obra está abierta a cualquier lectura, toda obra es una Grieta para la que cabe cualquier interpretación: y sólo por ello es posible la traducción». Esta apertura de la obra a lo que hay que nombrar ya en plural, a las interpretaciones, es propuesta claramente postestructuralista al dar la espalda a la existencia de un vínculo entre texto y sentido que conformase una estructura, en su lugar el sentido rompe su unidad y se desparrama en sentidos. Y este presupuesto teórico es, según Panero, lo que hace posible la traducción, una traducción que deberá trabajar «desarrollando los

\footnotetext{
54 PANERO, Leopoldo María, Cuentos completos sp., cit., p. 95.

55 PANERO, Leopoldo María, Cuentos completos, op. cit., pp. 247-248.

${ }^{56}$ PANERO, Leopoldo María, Visión de la literatura de terror angloamericana, op. cit., p. 34.

${ }^{57}$ PANERO, Leopoldo María, Traducciones/Perversiones, op., cit., p. 214 y 212, respectivamente.

58 PANERO, Leopoldo María, «Prólogo», Lewis CARROLL, Matemática demente, Barcelona, Tusquets, 1975, p.

7-72; la cita en p. 9.

59 Ibid., p. 9.
} 
sentidos latentes en el original, explicándolo (lo que en latín significa: desplegarlo)» ${ }^{60}$, que es, precisamente, lo que él hace en sus perversiones. En las palabras de Panero citadas es bien reconocible la procedencia de «Grieta»: Logique du sens (1969) de Deleuze, libro que seguirá utilizando en su prólogo, no en vano la obra de Lewis Carroll es una guía del mencionado libro deleuziano y son textos de Carroll los que Panero traduce en Matemática demente.

El prólogo en cuestión dedica cierto espacio a contestar algunas reseñas negativas que había suscitado la publicación de El ómnibus, sin sentido, críticas al hecho de que se trataba de una perversión o no haberlo entendido, y escribe:

Lo que, en resumen, dijeron esas «críticas» a una lectura Crítica es: que la función de la crítica ortodoxa es convertir la escritura en Literatura, y preservar los pobres, viejos y secos mitos de la división del trabajo (la principal causante de tantas identidades, «Obras», «autores», "géneros», Creación y traducción, etc.). ${ }^{61}$

Hablando sobre la traducción, Panero ha dado un salto y denuncia algunas de las nociones básicas del pensamiento literario tradicional que se prolongaron en el estructuralismo, un pensamiento tradicional que era ya estructuralista. Entre ellas no falta la estructura creación/traducción, es decir, escritura primera/escritura segunda, original/texto traducido, oposición que en la teoría paneresca y en su práctica, según ha quedado expuesto, resulta inane, vaciada de los rasgos que para muchos las caracterizan y, por tanto, sostienen. Si «bouche» es traducible, la perversión mediante, por «ano», o «an Old Lady» por «una niña», etc., si los originales, nombre ya de todo punto inadecuado, están ahí ofreciéndose a ser trasladados tanto como a ser corregidos, la consecuencia es que los designados como «pobres, viejos y secos mitos» de la teoría de la literatura son ya significantes que no encuentran correspondencia en algún significado, términos que, si bien pueden seguir siendo utilizados, no limitan ya concepto alguno. Y ello por cuanto lo que se predica con expresiones como original o texto primero le pertenece ahora por igual al texto traducido o segundo. Así lo afirma Panero al exponer lo que sería la perversión:

la traducción que hasta hoy ha sido considerada una labor anónima y humilde [...] es $\longrightarrow$ debe ser- por el contrario una operación literaria, creadora, si es que lo traducido es literatura y si se quiere, efectivamente, traducirlo; más creadora, literaria incluso, que el original traducido, puesto que (como — estúpidamente- se ha señalado tantas veces) la traducción es imposible. 62

y esa imposibilidad la hace posible la perversión, así como ésta hace también posible el que el texto resultante, donde se dan soluciones aparentemente extravagantes y aparecen pasajes que no corresponden con la literalidad del texto fuente, llegue a estar en relación de exactitud con el original. La perversión, al desarrollar los contenidos latentes, logra, por

una verdadera transmutación alquímica [...] la re-producción exacta del original: original que se perdería en una versión, en una traducción servil. La per-versión es, pues, la única traducción

\footnotetext{
${ }^{60}$ Ibid., p. 11.

${ }^{61}$ Ibid., p. 12.

62 Ibid., p. 15. Así lo afirma, entre otros, nada menos que Roman Jakobson, reconocida autoridad en la época: "poetry by definition is untranslatable. Only creative transposition is possible», «On linguistic aspects of translation», Selected wrintings, II. Word and language, La Haya-París, Mouton, 1972, p. 260-266; la cita en p. 266.
} 
literal o mejor dicho fiel al original: y esto lo logra mediante un adulterio, mediante su aparente— infidelidad. ${ }^{63}$

Dos son, pues, al menos, las salidas del sistema que Leopoldo María Panero propone en el prólogo a Matemática demente, por lo demás, íntimamente relacionadas: la superación de la estructura autor/traductor y la que en un régimen anterior distingue entre original y traducción. En ambos casos, los elementos antes en oposición son ahora equiparados en escritor y texto o escritura, respectivamente.

En un texto posterior, el prólogo a Visión de la literatura de terror anglo-americana, Panero volverá sobre la cuestión como si fuera bien consciente de lo problemático de sus planteamientos, problemático para críticos y lectores aferrados a, como él decía, el antiguo régimen literario, un régimen que en lo sustancial pervive, convendrá añadir. Un régimen, por otra parte, que en lo relativo a la figura del autor, ya había sido puesto en crisis por, entre otros, trabajos muy próximos en el tiempo, 1968 y 1969, de Roland Barthes y Michel Foucault, ya citado este anteriormente. Barthes daba cuenta ya en el título de su artículo de la muerte del autor. En efecto, «La mort de l'auteur» exponía cómo el autor había sido sustituido, ya en Mallarmé y su propósito de alcanzar la impersonalidad, por el lenguaje. Ese desplazamiento no era sin consecuencias. Una vez destituido el «Autor-Dios», como escribía Barthes ${ }^{64}$, el texto no quedaba vinculado a un sentido, ese un sentido sería teológico, sino por «un espacio de múltiples dimensiones en el que se concuerdan y se contrastan diversas escrituras, ninguna de las cuales es la original»y, así, el escritor «el único poder que tiene es el de mezclar escrituras ${ }^{65}$, que es exactamente lo que Panero hace en sus traducciones al introducir su discurso en el ajeno ya no tal, sino propio, a lo que habría que agregar su bien conocida práctica de incorporar a sus textos todo tipo de citas. Más adelante Barthes escribe, en la misma clave bajtiniana, cuál sería «el sentido total de la escritura» y explica:

un texto está formado por escrituras múltiples, procedentes de varias culturas y que, unas con otras, establecen un diálogo, una parodia, una contestación; pero existe un lugar en el que se recoge toda esa multiplicidad, y ese lugar no es el autor, como hasta hoy se ha dicho, sino el lector $[\ldots]$ el nacimiento del lector se paga con la muerte del Autor. ${ }^{66}$

Esta cuestión, la muerte del autor, está presente de forma explícita en el prólogo de Panero en Matemática demente. En los párrafos que dedica a rebatir las críticas, aunque casi sería mejor decir que a burlarse de ellas, que habían suscitado sus traducciones de Lear, explica que las incomprensiones de los críticos estarían basadas en su concepción de «la política autoritaria, la siniestra política de autores: aquel que compuso ese Ataúd que es, para esa gente, la Obra, es también un cadáver, un ser —el autor- idéntico a sí mismo, a cuyo

\footnotetext{
${ }^{63}$ Ibid., p. 17.

${ }^{64}$ BARTHES, Roland, «La muerte del autor», El susurro del lenguaje. Más allá de la palabra y la escritura, trad. C. FERNÁNDEZ MEDRANO, Barcelona, Paidós, 1994, 2ª ed., 65-71; la cita en p. 69.

65 Ibid., p. 69. Aunque Barthes no hace referencia a Mijaíl Bajtín, es evidente su eco en lo que dice. Julia Kristeva llegó al seminario de Barthes en L'École des Hautes Études en 1965 y, conocedora de la obra de Bajtín, fue quien se lo descubrió (Louis-Jean CALVET, Roland Barthes, Una biografía, trad. Alberto Luis Bixio, Barcelona, Gedisa, 2001, p. 168). Kristeva publicó varios trabajos que supusieron, con algunos otros más, la introducción de Bajtín en el ámbito francés, recogidos en Semeiotiké. Recherches pour une sémanalyse, París, Seuil, 1978, entre otros, el titulado «Bakhtine, le mot, le dialogue et le roman», que se había publicado previamente en Critique, 239, 1967, p. 438-465, anterior, por tanto, al de Barthes, de 1968, que cito en el texto.

66 Ibid., p. 71
} 
funeral asistimos por medio de su biografía» ${ }^{67}$. Obra: ataúd, Autor: cadáver. La muerte. La muerte del autor que en Barthes hace nacer al lector se repite en la teoría de la literatura de Panero y tal como se habla de ello en el prólogo a Visión de la literatura de terror angloamericana se puede pensar que conocía el artículo de Barthes, pues allí se lee que:

se está empezando a formular la lectura como lo que es, una reescritura [...], y como sistema, una ciencia: hoy tiene más valor un lector — que ha pasado a ser, en Francia, una de las formas de escritor- que un ingenuo «hacedor» (poeta, en griego). ${ }^{68}$

En cualquier caso, lo conociera o no - aunque ahí queda la referencia al pensamiento literario francés-, la idea es la misma.

Panero parte en ese texto de Maurice Blanchot, «escribir es producir la ausencia de obra», traducción de «Écrire, c'est produire l'absence d'œuvre (le désœuvrement)», que se lee en el capítulo «L'absence de livre» de L'entretien infini ${ }^{69}$, y hay que decir que la de Blanchot es en conjunto la obra clave del postestructuralismo, la obra de quien se adelanta al postestructuralismo, que lo adelanta. En sus escritos, muchos de ellos contemporáneos del periodo típicamente estructuralista, no hay ni asomo de estructuralismo y que su obra tuviese como lectores, entre otros, a las figuras centrales del postestructuralismo como son Barthes, Deleuze, Foucault y Jacques Derrida, en cuyos escritos no faltan referencias al pensamiento blanchotiano y textos que lo comentan y no puedo no aludir aquí a los muy importantes de Derrida — añádase que lo que puede denominarse como influencia circula también en sentido contrario-, es todo un índice inequívoco del lugar que ocupa Blanchot. Pues bien, Panero ha leído a Blanchot, inserta la mencionada cita en el comienzo de su trabajo y acudirá a otro de sus textos más adelante.

Aunque el asunto exige ser tratado con mayor extensión y detalle, sí al menos ha de consignarse que la muerte del autor, cuestión clave del estructuralismo al erosionar la estructura autor/obra, cuenta con la exposición, anterior a las aquí mencionadas, de Maurice Blanchot. En su «La littérature et le droit à la mort», publicado en dos artículos en 1947 y 1948, con apoyos en Hegel y Mallarmé, lecturas tan panerescas como también la de Blanchot, según se va diciendo en estas páginas, predica una muerte generalizada. La palabra aniquila la cosa que nombra: " quand je dis "cette femme", la mort réelle est annoncée est déjà présente dans mon langage [...] mon langage signifie essentiellement la possibilité de cette destruction [...] Il est donc précisément exact de dire, quand je parle : la mort parle en moi »; y el sujeto que habla tampoco se libra de la muerte: "Il est clair qu'en moi le pouvoir de parler est lié aussi à mon absence d'être. Je me nomme, c'est comme si je prononçais mon chant funèbre $»^{70}$. Y está además la frase justamente famosa: "Quand nous parlons, nous nous appuyons à un tombeau $»^{71}$. Baste esto.

De vuelta al pensamiento literario de Panero, ha de destacarse que un lugar central del trabajo de Panero al que me vengo refiriendo es la noción del Último Libro, idea derivada de la de Saber Absoluto de Hegel, quien no dejará de ser mencionado en esas páginas como también en las que el poeta ha citado, según se ha señalado, de Blanchot. Hegel concluye su Fenomenología del espiritu hablando del Calvario del Espíritu Absoluto,

\footnotetext{
${ }^{67}$ PANERO, Leopoldo María, Matemática demente, op. cit., p. 11.

${ }^{68}$ PANERO, Leopoldo María, Visión de la literatura de terror anglo-americana, op. cit., p. 28.

${ }^{69}$ BLANCHOT, Maurice, L'entretien infini, París, Gallimard, 1969, p. 622. En ese mismo prólogo se tiene en cuenta también el «Traduire» de Blanchot, trabajo incluido en L'amitié, París, Gallimard, 1971, p. 69-73.

70 BLANCHOT, Maurice, «La littérature et le droit à la mort», La part du feu, París, Gallimard, 1949 (2001), p. 291-331; las citas en p. 313.

${ }^{71}$ Ibid., p. 324.
} 
como antes, en «Fe y saber» había hablado del Viernes Santo Especulativo, y ambas expresiones las recoge Panero:

al otro lado de estos vestigios de «l'ancien régime», se esté empezando a formular la lectura como lo que es, una reescritura (véase la crítica literaria formalista o estructuralista) y como sistema, una ciencia [...]. Porque en esa lectura está más que en una «eyaculación infame» (una escritura apresurada, que no haya pasado por hacer propio todo lo que se ha escrito, a través de esa «rememoración»a la que Hegel —quien la postuló como la condición del Último Libro del Saber Absoluto— llamaba «el Calvario del Espíritu Absoluto» o «el Viernes Santo Especulativo»), la práctica y el concepto del Último Libro. Para esa práctica la lectura y con ella el acto de escribir que es su deudor y su «vasallo» real, y la literatura en su conjunto, son un sistema, del que los autores son sólo parásitos. No hay para ella «historia» lineal, sino sólo un espacio sincrónico, infinitamente reversible; no hay «historia» lineal, sino de tejido, en el que cada costura indica en la dirección de todos ellos. ${ }^{72}$

Vayamos antes de nada con alguna precisión que esta cita exige. Panero apela a la crítica literaria formalista o estructuralista: en cuanto a la primera, en su prólogo ha recurrido, unas páginas antes, a Víktor Shklovski y su concepto de extrañamiento, a lo que, entre otros lugares, también se recurre en el prólogo a El último hombre. Y está la cuestión de la mención de crítica «estructuralista»: hay que decir que Visión de la literatura de terror angloamericana se publicó en 1977 y que, aunque el postestructuralismo comienza a tomar cuerpo a finales de la década de los sesenta con trabajos de Barthes, Foucault, Deleuze, Jacques Lacan y de un modo más firme y explícito de Derrida además de publicaciones bastante anteriores de Blanchot, no fue inmediata la conciencia de la salida del estructuralismo y se continuó teniendo por estructuralistas planteamientos que ya no lo eran ${ }^{73}$. Por lo demás, lo que Panero está proponiendo es la eliminación del autor del sistema literario, su autoridad, el recurso a la biografía - cómo no recordar su «Que no usen mi torpe biografía para juzgarme» que dejó escrito en «Acerca de la literatura» ${ }^{74}$ - así como la eliminación de la historia literaria, basada casi como regla en la figura del autor, con su eje diacrónico, sustituida ahora por un «espacio sincrónico», lo que recuerda la idea de T. S. Eliot, expuesta en «Tradition and the individual talent», de que:

el sentido histórico implica que se percibe el pasado, no solo como algo pasado, sino como presente; y el sentido histórico obliga a un hombre a escribir no solo integrando a su propia generación en los propios huesos, sino con el sentimiento de que toda la literatura de Europa, desde Homero y dentro de ella, el conjunto de la literatura de su propio país, posee una existencia simultánea y constituye un orden simbólico. ${ }^{75}$

A esta concepción de la literatura Panero, una literatura sin autor, sin biografía, sin historia, la denominará literatura orgánica y todo ello exigido por la idea del Último Libro. Tal literatura es orgánica «por cuanto en ella no hay para la literatura referentes exteriores — la

\footnotetext{
72 PANERO, Leopoldo María, Visión de la literatura de terror anglo-americana, op. cit., p. 28. Quizá deba tenerse en cuenta que en «L'absence de livre» Blanchot establece un vínculo entre «Livre» y Hegel (BLANCHOT, Maurice, L'entretien infini, op. cit., p. 628-629).

${ }^{73}$ Baste lo que se dice en el texto sobre una cuestión que está reclamando una explicación mucho más extensa. ${ }^{74}$ PANERO, Leopoldo María, «Acerca de la literatura», Y la luz no es nuestra..., Valladolid, Los infolios, 1991, p. 11-14: la cita en p. 14; se reeditó con el mismo título en Madrid, Libertarias/Prodhufi, 1993. El artículo se había publicado antes en El País, 20 de junio de 1984, p. 25.

${ }^{75}$ ELIOT, T. S., El bosque sagrado, ed. José Luis PALOMARES, trad. Ignacio REY AGUDO, Madrid, Langre, 2004, p. 221.
} 
realidad o la vida— $\longrightarrow$ y así su «único referente es ella misma» ${ }^{76}$. Todo ello no será sin consecuencias, sino que ahora el plagio, práctica denostada que incluso ha adquirido en nuestro mundo carácter penal, y la traducción, esa escritura siempre menor, secundaria, adquieren una nueva valoración y ello por cuanto son ejercicios de lectura, es decir, no provienen de un afuera, sino de la literatura misma y son, por tanto, las posibilidades verdaderamente orgánicas. Con ello las estructuras original/plagio y original/traducción quedan lógicamente desestructuradas, equiparados los miembros de lo que en ellas se presenta en oposición y que ahora nada los diferencia.

(Un paréntesis sobre la cuestión del plagio, de la escritura como reescritura en su significado más directo, como usurpación — término este que utiliza Panero: «Para la literatura orgánica no hay más culto al autor que el de su lectura. Es decir, el de su elaboración como alteridad, el de su usurpación» ${ }^{77}$ - Ignacio Prat, coetáneo y amigo de Panero en torno a 1970 y a quien debería el título de Así se fundó Carnaby street, dejó unos estudios literarios de primer orden y una obra literaria del mismo rango. Por lo que lo traigo aquí es porque practicó la reescritura como muy pocos. Entre sus plagios merece destacarse el titulado «Las intrigas venecianas o el síndrome Myslowitz-Braunschweig». Esta prosa es reescritura ad pedem litterae en su primera mitad de «Intrigas venecianas o fray Gregorio de Jerusalén. Ensayo de una novela española» de José María Blanco White que se continúa con la copia de «Myslowitz-Braunschweig-Marsella. Historia de una embriaguez de haschisch» de Walter Benjamin, siendo las aportaciones textuales de Prat mínimas. Caso singularísimo de apropiación y autoría híbrida ${ }^{78}$.)

Leopoldo María Panero, defendiendo sus libertades o liberalidades como traductor o pervertidor, ha pasado a presentar todo un conjunto teórico postestructuralista, lo que en la academia española de la época — recuérdese que el prólogo en cuestión se publica en 1977_ - y aun fuera de ella, e incluso en buena parte todavía hoy, resultaba tan innovador, tan extraño, tan desconectado de las teorías dominantes, que sólo podía aspirar a la incomprensión. Y, si popularizada la imagen del poeta como extravagante o directamente loco, a lo que colaboró, entre otras cosas, su participación en El desencanto (1976), juicios críticos, por darles todavía ese nombre y ese adjetivo, de semejante naturaleza no tenían fundamento ninguno en el conjunto de la literatura orgánica, una literatura sin autor, sin biografía, bases sobre las que aquéllos deberían asentarse.

Cuando Panero hace explícitas las consecuencias de su pensamiento literario y escribe que:

La literatura orgánica, a comenzar por Lautréamont, otorga a la cita, a la lectura y a la traducción el máximo valor, como los más arriesgados exponentes de la naturaleza sistemática de la literatura. Y considera a la traducción lo mismo que a la cita y a la lectura, como lo que son, reescrituras, ya por el solo hecho de inscribir a lo que citan, leen o traducen, en otro

\footnotetext{
76 PANERO, Leopoldo María, Visión de la literatura de terror anglo-americana, op. cit., p. 28.

77 PANERO, Leopoldo María, ibid., p. 29.

78 PRAT, Ignacio, Para ti. 1963-1981, ed. José Luis JOVER, Valencia, Pre-textos, 1982, p. 131-137; según anota Jover, el mencionado texto, que permaneció inédito hasta la citada edición, habría sido escrito en 1976 (p. 179, n. 28); véase además mi libro Scriptor ludens. Ensayo sobre la poesía de Ignacio Prat, Zaragoza, Lola editorial, 1990, y mi artículo «Escritura sin escritura: doble escritura», Jinzo. Revista de bumanidades, 6-7, primavera-verano 2008, p. 39-47. Siendo escritor muy poco leído y casi olvidado, no estará de más recordar que Pere Gimferrer lo incluyó en lo que llamó «ala extrema de la poesía novísima», que estaría formada por Ignacio Prat, Leopoldo María Panero, Félix de Azúa y Francisco Ferrer Lerín (GIMFERRER, Pere, «Frontispicio», Francisco FERRER LERÍN, Cónsul, Barcelona, Edicions 62, 1987, p. 7-8; la cita en p. 7). De Ferrer Lerín y también de José-Miguel Ullán debería citarse aquí alguno de sus textos como prácticas de reescritura.
} 
tiempo y en otro contexto cultural que aquel que les vio nacer, aquel en que se «crearon»: como Pierre Menard hacía con su Quijote, del que no olvidemos, era uno de los autores ${ }^{79}$,

corría el riesgo de ser recibido como falto de sentido, para decirlo parafraseando la célebre y certera afirmación de Derrida de que «Un poema corre el riesgo siempre de no tener sentido, y no sería nada sin ese riesgo», frase, por cierto, que Panero recoge en el prólogo al que me vengo refiriendo y en numerosos otros lugares de su obra ${ }^{80}$. Corría el riesgo...y así fue y es que la propuesta de una literatura orgánica habría de encontrar, no sé si curiosamente, por parte del sistema académico, o por buena parte de él, una resistencia muy semejante a la que vienen suscitando los trabajos de Derrida. Por otra parte y como es claro, la mención de Pierre Menard lo es al texto de Ficciones de Jorge Luis Borges «Pierre Menard, autor del Quijote», donde el personaje, que quizá no había leído íntegra la novela de Cervantes según se dice, escribe de nuevo, reescribe aunque será un texto otro, dos de sus capítulos y un fragmento de un tercero, imagen luminosa del escritor contemporáneo. Borges comparece en otra ocasión en el trabajo de Panero en una cita que vuelve sobre la cuestión de la lectura y, siendo la lectura los cimientos del edificio, la cita, reescritura. Escribe Panero que «como dijo Borges, la literatura lo mismo que el lenguaje es "un sistema de citas" », frase entrecomillada que es cita evidente de la afirmación de Eudoro Acevedo, el personaje de «Utopía de un hombre que está cansado»: «Ya no nos quedan más que citas. La lengua es un sistema de citas» ${ }^{81}$. Un sistema de citas es lo que es la literatura orgánica.

Literatura orgánica en cuanto literatura sin autor, escritura tras la muerte del autor. Entre las prácticas de tal ideario, su tarea de traductor. Trabajo de lectura y de escritura que sólo puede ser ya reescritura, un trabajo en el que se corrige el original, se añaden pasajes, se da la espalda a las equivalencias que dictan los diccionarios para así perfeccionar, hacer surgir los sentidos latentes y dar al lector textos que no pueden ser ya nombrados como traducciones, sino como perversiones, textos atravesados por la doble firma, una doble firma que hace que junto a la firma del autor se haya producido la «Inscripción del traductor que se superpone a la del autor del original en una doble inscripción. Doble inscripción, doble traza, doble firma» ${ }^{82}$.

Una visión de la literatura la de Panero que, como hemos visto, estaba fundamentada en lecturas de Blanchot, Barthes —y en su trasfondo Bajtín—, Foucault, Derrida, además de Borges, lecturas que inauguraban el giro del estructuralismo al postestructuralismo, una idea de la literatura a la que Panero dio el nombre de literatura orgánica.

Una literatura orgánica, tal como se muestra en la práctica literaria de Leopoldo María Panero, en la que los términos que designan las formas textuales, que dan nombre a una serie de reglas, prescripciones, aparecen con un uso desviado, por el cual «haiku» ya no

\footnotetext{
79 PANERO, Leopoldo María, ibid., pp. 29-30.

80 DERRIDA, Jacques, La escritura y la diferencia, trad. Patricio PEÑALVER, Barcelona, Anthropos, 1989, p. 101. PANERO, Leopoldo María, «el poema "corre siempre el riesgo de carecer de sentido, y no sería nada sin ese riesgo"», ibid., p. 11. Como queda a la vista, la edición española es varios años posterior a la publicación de Visión de la literatura de terror anglo-americana, de manera que Panero hubo de conocer el texto en francés, cuya edición en Les Éditions du Seuil es de 1967.

${ }^{81}$ BORGES, Jorge Luis, El libro de arena, Madrid, Alianza Editorial, 1975, p. 73. PANERO, Leopoldo María, ibid., p. 29. Panero incluye en esas mismas páginas: «Esta sería la literatura — que consideraría, de hacerse, como su buena figura a Borges - "de la posibilidad agotada", como bien dice John Barth a propósito de Borges, la literatura que explore las posibilidades inexistentes que quedan para una literatura nueva» (PANERO, Leopoldo María, ibid., p. 23); el trabajo de Barth al que se alude es evidentemente su «The literature of exhaustion» (The Atlantic Monthly, 220, agosto, 1967, p. 29-34).

82 BLESA, Túa, «Teoría y práctica de la traducción como perversión», op. cit., p. 7-39; la cita en p. 39.
} 
se corresponde con poemas que, al menos, deberían constar de tres versos de, respectivamente, cinco, siete y cinco sílabas y la preceptiva palabra de estación - ya la correspondencia se rompa con uno de tales preceptos, ya con más de uno o todos ellos-, ni tampoco «limerick» con lo que la norma del limerick dicta, una escritura en la que «prosa» es título de un conjunto de versos y «proyecto» es ya la denominación de un texto publicable y publicado, definitivo, a la par que las instrucciones para escribir ese texto proyectado, términos para prescripciones que dan lugar a las prescripciones prescritas. Así, las estructuras del sistema quedan desestructuradas y con ello el sistema mismo resulta desistematizado.

Del mismo modo, los escritos memorialísticos de Panero, los que han de decir verdad y de los que en ellos mismos se afirma que dicen la verdad, lo verificable, incluyen frases en las que ese principio genérico queda más que malparado. En tales páginas autobiográficas, lo hemos visto, parte de lo narrado se acomoda a la historia, dice verdad, y otras partes, "Yo he matado a Jean-Paul Sartre, poseyéndolo como a una muñeca hinchable, como un escarabajo, que eso es lo que era», por ejemplo, no cumplen con el precepto de la autobiografía y reclaman la asunción de un extraño género que se podría, o debería, llamar «autobiografía fantástica», valga el oxímoron, en cualquier caso una ocurrencia más de prescripciones.

Al dictado del Último Libro, Panero, a la par que escribió sus libros, los libros con la firma «Leopoldo María Panero», dejó su firma en varios otros, hasta doce, cuya autoría es la de «Leopoldo María Panero y X», en los que la escritura es a dúo, como decían Deleuze y Guattari que habían escrito L'Anti-Oedipe, y «escritura a dúo» es parte del título de Jardín en vano y «Escribir a dúo» se lee en el prólogo de Presentación del Superbombre, dos de los libros de autor doble, según ya se ha señalado. Retomando ahora palabras de éstos, citadas más arriba, en la serie poética de Leopoldo María Panero y X se trataría de «No llegar al punto de ya no decir yo, sino a ese punto en el que ya no tiene ninguna importancia decirlo o no decirlo. Ya no somos nosotros mismos», de plantear la pregunta ¿quién soy yo?, como reza uno de los títulos de la serie, para que la pregunta quede ahí, enunciada, inquisitiva, sin que por ello esté a la espera de respuesta, pura interrogación. 